\title{
Ring-Based WDM Access Network Providing Both Rayleigh Backscattering Noise Mitigation and Fiber-Fault Protection
}

\author{
C. H. Yeh, Member, IEEE, C. W. Chow, Member, IEEE, S. P. Huang, J. Y. Sung, Y. L. Liu, and \\ C. L. Pan, Fellow, IEEE, OSA
}

\begin{abstract}
In this paper, we propose and investigate a ring-based wavelength-division-multiplexing passive optical network (WDM-PON) providing both Rayleigh backscattering (RB) noise mitigation and fiber-fault protection. The proposed ring-based WDM-PON has a dual-ring architecture to protect and restore any fiber fault. Besides, the ring architecture also can mitigate the $R B$ beat noise, since the $R B$ and the upstream wavelengths are propagating in opposite directions. Here, we discuss and analyze the characteristics of the downstream signals using 10 Gb/s ON-OFF keying (OOK), $10 \mathrm{~Gb} / \mathrm{s}$ differential phase-shift keying, and $10 \mathrm{~Gb} / \mathrm{s}$ orthogonal frequency-division multiplexing (OFDM) modulations, respectively. Moreover, we also investigate the upstream traffic using the $2.5 \mathrm{~Gb} / \mathrm{s} \mathrm{OOK}$ and $10 \mathrm{~Gb} / \mathrm{s}$ OFDM generated by the directly modulated reflective semiconductor optical amplifier-based optical network unit, respectively.
\end{abstract}

Index Terms-Differential phase-shift keying (DPSK), fiber-fault protection, ON-OFF keying (OOK), orthogonal frequency-division multiplexing (OFDM), ring access, wavelengthdivision-multiplexing passive optical network (WDM-PON).

\section{INTRODUCTION}

B ECAUSE of the rapid growth in the demand of broadband multiservices, passive optical network (PON) is a promising solution for the future fiber access systems [1]-[4]. Furthermore, wavelength-division-multiplexed passive optical networks (WDM-PONs), using directly modulated laser (DML) at the central office (CO) [5], [6] and reflective semiconductor optical amplifier (RSOA) for signal reuse and remodulation at each optical network unit (ONU) [7], [8] are desirable system architectures for the future high-speed and high-capacity PON [9]. However, in colorless WDM-PON system, the Rayleigh backscattering $(\mathrm{RB})$ interferometric beat noises will be generated by the downstream signal and result in impairment of net-

Manuscript received June 18, 2012; revised August 01, 2012, August 14, 2012; accepted August 16, 2012. Date of publication August 24, 2012; date of current version October 03, 2012.

C. H. Yeh and Y. L. Liu are with the Information and Communications Research Laboratories, Industrial Technology Research Institute, Hsinchu 31040, Taiwan.

C. W. Chow, S. P. Huang, and J. Y. Sung are with the Department of Photonics and the Institute of Electro-Optical Engineering, National Chiao Tung University, Hsinchu 30010, Taiwan (e-mail: cwchow@faculty.nctu.edu.tw).

C. L. Pan is with the Department of Physics and the Institute of Photonics Technologies, National Tsing Hua University, Hsinchu 30013, Taiwan.

Color versions of one or more of the figures in this paper are available online at http://ieeexplore.ieee.org.

Digital Object Identifier 10.1109/JLT.2012.2214374 work performance [10], [11]. Hence, in order to reduce the RB interferometric beat noise, different $\mathrm{RB}$ mitigation techniques have been proposed and discussed, such as using the phase and bias-current dithering, utilizing wavelength-shifting technique, employing advanced modulation formats, using double laser bands source, etc. [11]-[15]. However, these proposed methods would increase the complexity and the cost of PON. In addition, these proposed techniques were mainly employed in tree-based WDM-PONs.

Furthermore, to enhance the spectral efficiency and reduce the cost of high-speed transmitters (Tx) and receivers $(\mathrm{Rx})$, optical orthogonal frequency-division multiplexing quadrature amplitude modulation (OFDM-QAM) has been proposed and reported [16]-[20]. And this modulation format could be a promising candidate for the future WDM-PONs.

Next-generation WDM-PON must provide high quality of service and reliability. When the fiber between the $\mathrm{CO}$ and each ONU is broken in WDM-PONs, the data traffic cannot reach the affected ONU, leading to data loss. Hence, the protection management of fiber fault is one of the critical issues in PON access [21]-[24]. Furthermore, the ring-based TDM- and WDM-PON has been actively studied [2], [25]-[28] and is regarded as one of the important architectures for next-generation PON.

In this paper, we propose and experimentally demonstrate the ring-based WDM-PON system with the RB noise mitigation and fiber-fault protection. Here, we propose a new design in each RSOA-based ONU to produce the downstream and upstream traffic propagating in opposite directions. Consequently, advanced modulation techniques are not required for mitigation of the RB noise. In the proposed architecture, dual fiber ring configuration is used to protect the occurrence of fiber fault. Besides, each ONU can select the fiber path automatically to transmit the data traffic. In this paper, the downstream 10 $\mathrm{Gb} / \mathrm{s}$ differential phase-shift keying (DPSK), ON-OFF keying (OOK) and OFDM signals, and the upstream $2.5 \mathrm{~Gb} / \mathrm{s}$ OOK and $10 \mathrm{~Gb} / \mathrm{s}$ OFDM upstream signals by using RSOA-based ONU have been achieved and analyzed, respectively.

\section{FiBER-FAult Protection}

First, a ring-based WDM-PON architecture with fiber-fault protection and RB noise mitigation is proposed, as illustrated in Fig. 1. In the $\mathrm{CO}$, the downstream and $\mathrm{CW}$ signals are combined via a blue/red-band filter (BRF) and transmitted through a WDM multiplexer and a $1 \times 2$ optical coupler and then into each ONU in counterclockwise (CCW) direction. Here, each 


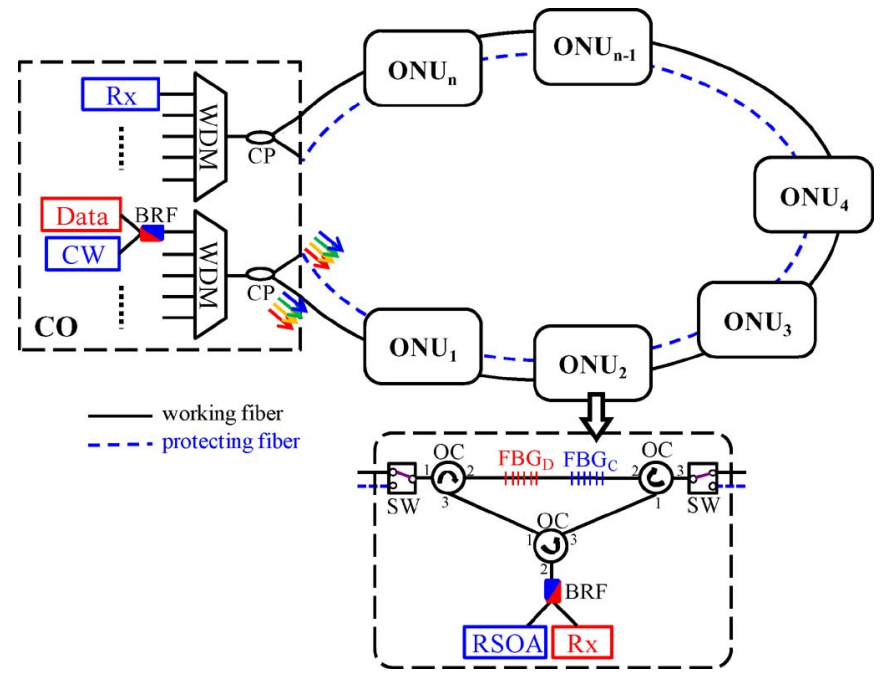

Fig. 1. Proposed ring-based WDM-PON architecture. Black solid line: working fiber; blue dash line: protecting fiber.

ONU consists of three optical circulators (OCs), two $1 \times 2$ optical switches (SWs), a BRF, an optical transceiver (TRx), and two fiber Bragg gratings $\left(\mathrm{FBG}_{\mathrm{D}}\right.$ and $\left.\mathrm{FBG}_{\mathrm{C}}\right)$. The two $\mathrm{FBGs}$ are used to reflect the corresponding downstream and $\mathrm{CW}$ signals into the TRx for data receiving and upstream signal generation, respectively. Besides, in the newly designed ONU, the TRx consists of a $1.2 \mathrm{GHz}$ bandwidth RSOA and $2.5 \mathrm{GHz}$ PIN receiver, respectively. Further, the downstream and $\mathrm{CW}$ signals are separated by a BRF for launching into the PIN and RSOA in that order. Therefore, the RSOA will modulate the $\mathrm{CW}$ signal to generate the upstream signal. In the signal transmission path, the upstream signal will also be reflected by the $\mathrm{FBG}_{\mathrm{C}}$ and transmitted through the $\mathrm{CCW}$ direction into the $\mathrm{CO}$. As a result, the backscattered $\mathrm{CW}$ signal and the upstream signal propagate in two different directions. The RB noise is thus mitigated. Besides, the proposed ring-based WDM-PON scheme can also support wavelength remodulation schemes to enhance the wavelength efficiency effectively. These can be done by using the DPSK as downstream signal and OOK as upstream signal [29] or using the OFDM as downstream signal and OOK as upstream signal [11].

The proposed ring-based network could be one of the promising architectures for the next-generation access due to the flexible wavelength assignment. More than one wavelength can be assigned to an ONU to increase its capacity. Also the network scalability can be improved. Besides, the ring-based network can provide network protection. Recently, ring-based networks have been studied in Europe (EU projects) [31], [32], the U.S. [33], Japan [34], etc. Besides, the insertion loss of the proposed network can be compensated by using optical amplifiers.

Fig. 2 shows a schematic diagram of the design of the ONU with flexible wavelength assignment together with optical amplifiers to compensate the insertion loss. By using several tunable FBGs, flexible wavelength assignment and management can be achieved.

Here, we discuss the fiber-fault protection mechanism. In this proposed architecture, there are two fiber paths: the working

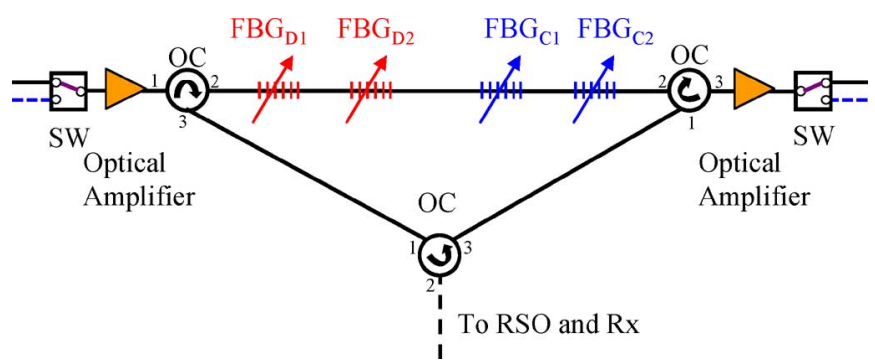

Fig. 2. Schematic diagram of the design of the ONU with flexible wavelength assignment.

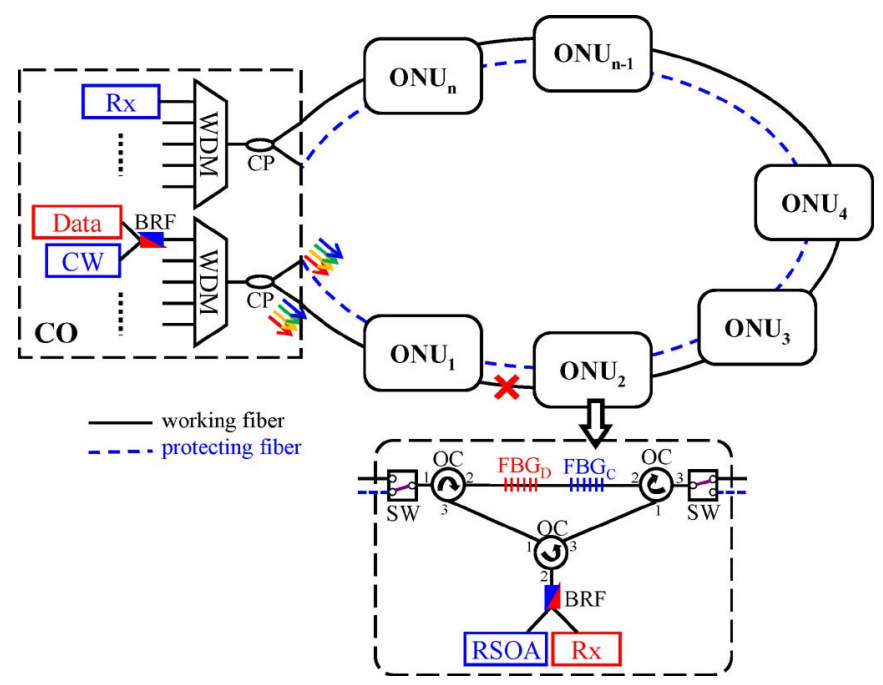

Fig. 3. Scenario in which a fiber fault occurs between $\mathrm{ONU}_{1}$ and $\mathrm{ONU}_{2}$ in our proposed ring-based WDM-PON system.

(black solid line) and protecting (blue dash line) fiber paths. Two SWs of each ONU are connected to the working fiber path (black solid line) for the downstream and CW signals initially, as shown in Fig. 1, when there is no fiber fault. Besides, the downstream and $\mathrm{CW}$ signals could not pass through the protecting fiber due to the isolation of SW in each ONU, as also shown in Fig. 1.

If a fiber fault occurs between $\mathrm{ONU}_{1}$ and $\mathrm{ONU}_{2}$, as shown in Fig. 3, the entire data link cannot be connected after the $\mathrm{ONU}_{1}$. Thus, self-protection will be an important issue. If the proposed PON system is a single-ring architecture, the data traffic will be disconnected for all the ONUs after the $\mathrm{ONU}_{1}$. To overcome this problem, we propose a dual-ring WDM-PON architecture with a new optical module in each ONU. To protect and restore the fiber fault in the proposed PON, each ONU can automatically switch the direction of $1 \times 2 \mathrm{SW}$ depending on whether its receiver $(\mathrm{Rx})$ receiving the corresponding downstream signal or not. If the ONU-Rx does not receive the downstream signal, the SW will switch automatically to reconnect the downstream and $\mathrm{CW}$ signals.

As shown in Fig. 3, when a fault occurs between $\mathrm{ONU}_{1}$ and $\mathrm{ONU}_{2}$, the units from $\mathrm{ONU}_{2}$ to $\mathrm{ONU}_{n}$ cannot receive any downstream and $\mathrm{CW}$ signals. At this moment, the two SWs in these ONUs can switch the signals to the protecting fiber for 


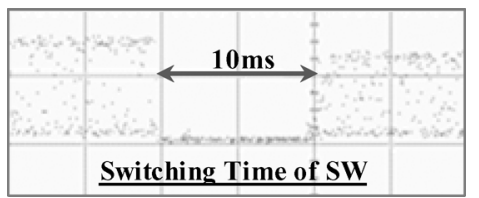

Fig. 4. Protection and restoration time of the proposed self-protected ringbased PON.

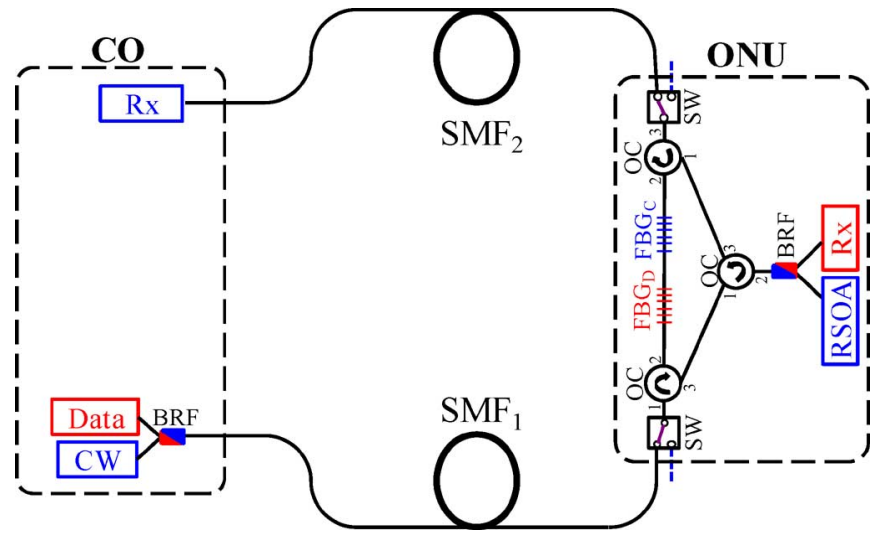

Fig. 5. Experimental setup for the proposed ring-based WDM-PON configuration.

reconnecting immediately. Hence, the proposed network architecture and optical modules can protect and restore the communication channel upon the occurrence of a fiber fault. Besides, the new optical module design in each ONU can also minimize the RB beat noise via the ring architecture.

In this study, we also measured switching time of the SW, which is used in each ONU in the proposed self-protected ringbased WDM-PON system for self-protection and restoration. For such measurement, switching time of the SW was determined within $10 \mathrm{~ms}$ of the occurrence of a fiber fault in the working fiber, as shown in Fig. 4.

\section{UPSTREAM ANALYSIS}

In this section, we will discuss and analyze the modulated upstream signal using the $1.2 \mathrm{GHz}$ bandwidth-RSOA-based ONU via the OOK and OFDM-QAM modulations using distributed $\mathrm{CW}$ injection. Fig. 5 shows the experimental setup for the proposed ring-based WDM-PON configuration. In the experiment, the downstream and $\mathrm{CW}$ signals were combined via a BRF for signal transmissions. The $\mathrm{CW}$ signal from the $\mathrm{CO}$ transmitted through the $\mathrm{SMF}_{1}$ (working fiber), $\mathrm{SW}$ and $\mathrm{OC}$, and was reflected by the $\mathrm{FBG}_{\mathrm{C}}$. The reflected wavelength also transmitted through two OCs and a BRF, and then launching into RSOA for modulation, as shown in Fig. 5. Besides, the modulated upstream signal also was reflected by the $\mathrm{FBG}_{\mathrm{C}}$ and transmitted through the $\mathrm{SMF}_{2}$ (working fiber), and then back to the CO.

In this measurement, the $\mathrm{CW}$ signal at a wavelength of 1550.6 $\mathrm{nm}$ was set at $7 \mathrm{dBm}$. The $\mathrm{CW}$ signal was generated from a distributed feedback laser diode (DFB-LD) with linewidth of 10 $\mathrm{MHz}$. The RSOA (produced by $C I P$ ) was operated at a bias current of $50 \mathrm{~mA}$. The transmission lengths of $\mathrm{SMF}_{1}$ and $\mathrm{SMF}_{2}$ were 5 and $20 \mathrm{~km}$, respectively. The reflectivity and reflected Bragg wavelengths of $\mathrm{FBG}_{\mathrm{D}}$ and $\mathrm{FBG}_{\mathrm{C}}$ are $99.3 \%$ and 1532.2

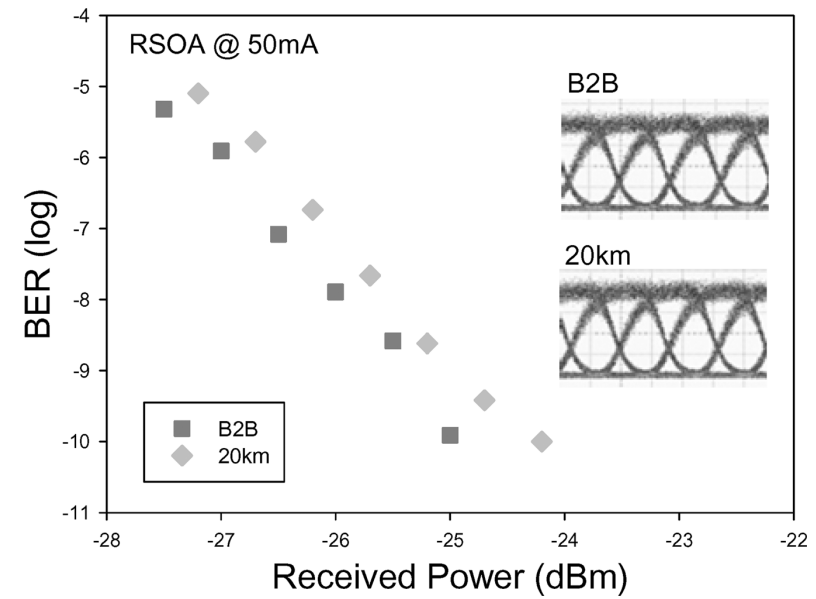

Fig. 6. BER performance of $2.5 \mathrm{~Gb} / \mathrm{s}$ OOK upstream signal at $\mathrm{B} 2 \mathrm{~B}$ and after $20 \mathrm{~km}$ fiber transmission. Insets are measured corresponding eye diagrams.

$\mathrm{nm}$, and $99.0 \%$ and $1550.6 \mathrm{~nm}$ respectively. First, we will discuss the results for OOK modulation upstream traffic. Here, the RSOA was direct modulated by nonreturn-to-zero (NRZ) data of pseudorandom binary sequence (PRBS) with pattern length of $2^{31}-1$ at a $2.5 \mathrm{~Gb} / \mathrm{s}$ to produce the OOK format. The upstream signal was launched back to the $\mathrm{CO} \mathrm{Rx}$ for bit error rate (BER) measurements through the $\mathrm{SMF}_{2}$. Moreover, an optical preamplifier, which consisted of a variable optical attenuator (VOA) and an erbium-doped fiber amplifier (EDFA), was used in the $\mathrm{CO}$ to measure the BER. Fig. 6 shows the BER performance of $2.5 \mathrm{~Gb} / \mathrm{s}$ OOK upstream signal at back-to-back (B2B) and after transmission over $20 \mathrm{~km}$ of fiber. As shown in Fig. 6 , the Rx sensitivity was $-24.7 \mathrm{dBm}$ and the power penalty was $0.4 \mathrm{~dB}$. The insets of Fig. 6 are the corresponding eye diagrams. These eyes are clean and wide opening. Furthermore, to achieve $20 \mathrm{~km}$ SMF transmission, $\mathrm{CW}$ injection power required is $>-10 \mathrm{dBm}$.

Then, we will investigate and discuss the optical OFDM modulation applying to the RSOA for signal modulation. As the modulation speed of the RSOA is limited to about $1.2 \mathrm{GHz}$, to achieve a higher upstream data rate, the optical OFDM-QAM modulation has been proposed due to its highly spectral efficiency.

First, we need to investigate the effects of $\mathrm{CW}$ injection power on BER performance, when 64-QAM OFDM modulation is applied in the RSOA. In the experiment, the baseband electrical OFDM upstream signal was generated by an arbitrary waveform generator (AWG) utilizing the MATLAB program. The signal processing of the OFDM transmitter consisted of serial-to-parallel conversion, QAM symbol encoding, inverse fast Fourier transform (IFFT), cyclic prefix (CP) insertion, and digital-to-analog conversion (DAC). 12 GSample/s sampling rate and 8-bit DAC resolution were set by the AWG, and $\mathrm{CP}$ of $1 / 64$ was used. Thus, 72 subcarriers of 64-QAM format occupy nearly $1.66 \mathrm{GHz}$ bandwidth of 0.26 to $1.92 \mathrm{GHz}$, with a fast Fourier transform (FFT) size of 512. Here, yielding $\sim 22$ $\mathrm{MHz}$ subcarrier spacing and $10 \mathrm{~Gb} / \mathrm{s}$ total data rate could be observed. Hence, the produced electrical 64-QAM OFDM signal could be applied on the RSOA via a bias-tee. Besides, the upstream signal was direct detected via a $2.5 \mathrm{GHz}$ PIN 


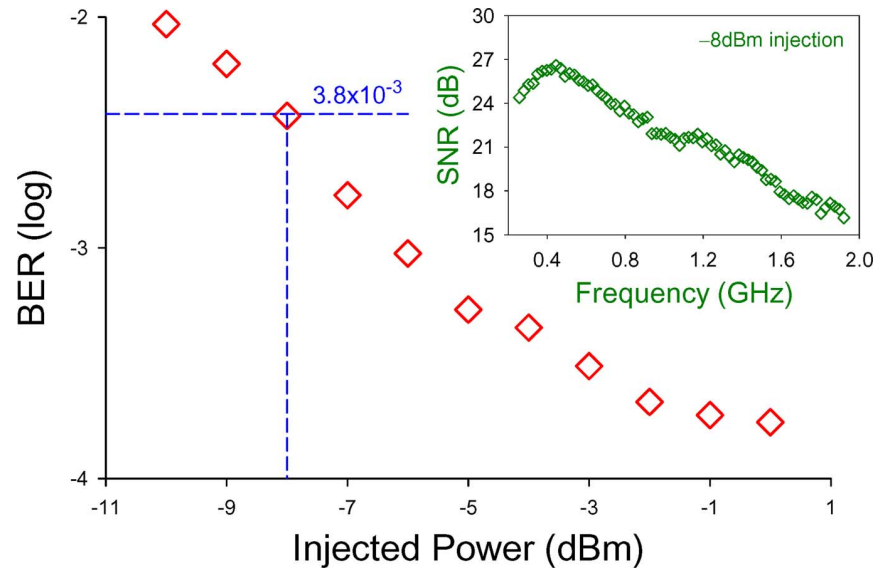

Fig. 7. BER measurements of RSOA-based ONU after $20 \mathrm{~km} \mathrm{SMF}_{2}$ transmissions, under the different $\mathrm{CW}$ injection power range of -10 to $0 \mathrm{dBm}$. The inset is corresponding SNR of each OFDM subcarriers while a injection power is $-8 \mathrm{dBm}$.

receiver at the $\mathrm{CO}$. The received OFDM signal was captured by a real-time oscilloscope, with $3 \mathrm{~dB}$ bandwidth of $12.5 \mathrm{GHz}$ and sampling rate of $50 \mathrm{GSample/s}$, for signal demodulation. To demodulate the vector signal, the offline DSP program was employed. And the demodulation process contained the synchronization, FFT, one-tap equalization, and QAM symbol decoding. Signal-to-noise ratio (SNR) was obtained by measuring the signal power compared to the noise power of each OFDM symbol. Then, the average SNR was calculated by averaging the SNRs of all the OFDM subcarriers. Finally, the BER was calculated based on the average SNR using the equation described in [35]. Furthermore, the entire measured subcarriers can achieve the forward error correction (FEC) threshold, with a BER of $3.8 \times 10^{-3}(\mathrm{SNR}=21.2 \mathrm{~dB})$ and redundancy ratio of $\sim 7 \%$ [4].

Fig. 7 shows the measured BER performance of $10 \mathrm{~Gb} / \mathrm{s}$ OFDM RSOA-based upstream signal after $20 \mathrm{~km}$ of $\mathrm{SMF}_{2}$ transmission, under different $\mathrm{CW}$ injection power of 0 to -10 $\mathrm{dBm}$. The received power at the $\mathrm{CO}$ is set at $-8 \mathrm{dBm}$. As shown in Fig. 7, with the gradual increase of injection power, the obtained BER also improved. This is because the rise in relaxation oscillation frequency of the RSOA with injection power. The relaxation oscillation frequency of RSOA can be increased by optical injection [11]; hence, higher optical power can increase the modulation speed of the RSOA. Therefore, the $3 \mathrm{~dB}$ bandwidth of RSOA also can be enhanced via the CW injection. Here, to achieve the FEC threshold after $20 \mathrm{~km}$ of $\mathrm{SMF}_{2}$ transmission, the minimum $\mathrm{CW}$ injection powers must be larger than $-8 \mathrm{dBm}$, as illustrated in Fig. 7. Moreover, the inset of Fig. 7 plots the SNR of each OFDM subcarrier in the frequency bandwidth of $0.26-1.92 \mathrm{GHz}$ at the injection power of $-8 \mathrm{dBm}$ launching into RSOA. The average SNR of each OFDM subcarrier is larger than $22.5 \mathrm{~dB}$ at $64-\mathrm{QAM}$ modulation. Thus, the measured BER can achieve FEC threshold.

When the $\mathrm{CW}$ injection power is $-8 \mathrm{dBm}$, the BER measurement of 64-QAM OFDM upstream signal for the directly modulated RSOA is measured at the B2B and after $20 \mathrm{~km}$ of $\mathrm{SMF}_{2}$ transmission, respectively, as seen in Fig. 8. The insets of Fig. 8 are corresponding constellation diagrams. In Fig. 8, we

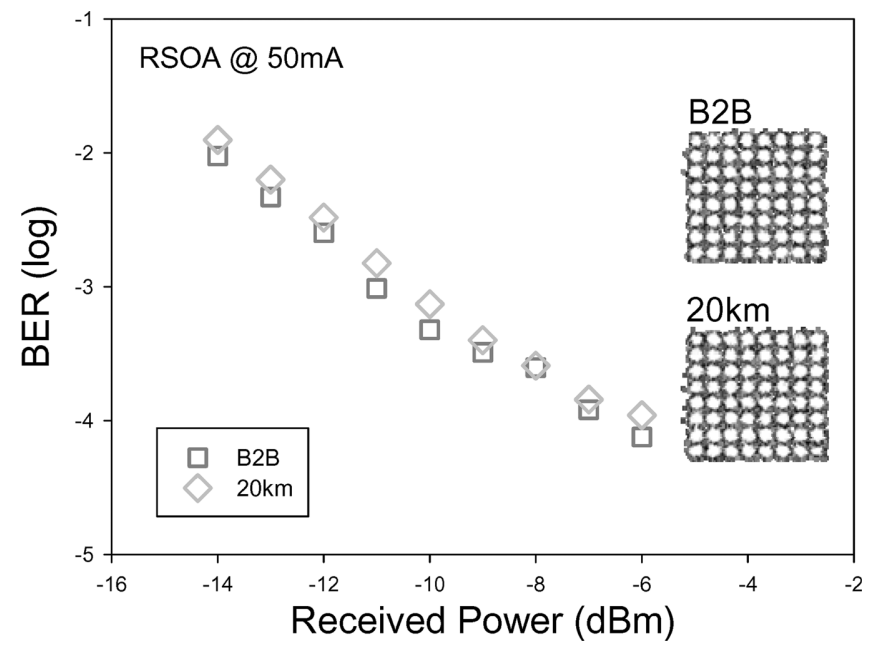

Fig. 8. BER measurement of 64-QAM OFDM upstream signal is measured at the $\mathrm{B} 2 \mathrm{~B}$ and $20 \mathrm{~km} \mathrm{SMF}_{2}$ transmission, respectively, when the $\mathrm{CW}$ injection power is $-8 \mathrm{dBm}$.

can determine the corresponding received powers at -12.5 and $-12.4 \mathrm{dBm}$, respectively, at the FEC threshold. We achieved negligible power penalty after $20 \mathrm{~km} \mathrm{SMF}_{2}$ transmission at the BER of $3.8 \times 10^{-3}$.

We also conducted comparisons of $2.5 \mathrm{~Gb} / \mathrm{s}$ OOK and 10 $\mathrm{Gb} / \mathrm{s}$ 64-QAM OFDM modulations by using the same $1.2 \mathrm{GHz}$ bandwidth RSOA for upstream traffic. The injection powers are -10 and $-8 \mathrm{dBm}$ for the $20 \mathrm{~km}$ fiber link, respectively. Besides, the measured sensitivities are -24.7 and $-12.4 \mathrm{dBm}$. Using OFDM modulation can increase the upstream data rate by four times when compared with the OOK format. On the other hand, it also results in the received sensitivity to drop by half, as shown in Figs. 6 and 8.

\section{DOWNSTREAM TRAFFIC}

In this section, we reported the experimental results investigated by using three modulation formats, which are $10 \mathrm{~Gb} / \mathrm{s}$ OOK, $10 \mathrm{~Gb} / \mathrm{s}$ DPSK, and $10 \mathrm{~Gb} / \mathrm{s}$ 16-QAM OFDM, respectively, for the downstream traffic. All the BER measurements are based on optical preamplifier Rxs.

First, we performed the $10 \mathrm{~Gb} / \mathrm{s}$ OOK downstream experiment using the experimental setup of Fig. 5. In the CO, the 10 $\mathrm{Gb} / \mathrm{s}$ downstream signal was achieved by using a DFB-LD with $10 \mathrm{~Gb} / \mathrm{s}$ external OOK modulation. The $1532.2 \mathrm{~nm}$ DFB-LD has $\sim 8 \mathrm{dBm}$ output power. A $10 \mathrm{GHz}$ Mach-Zehnder modulator (MZM) was used to generate OOK format. The insertion loss of MZM was around $6 \mathrm{~dB}$. Here, the DFB-LD was modulated at $10 \mathrm{~Gb} / \mathrm{s}$ with a NRZ format, with PRBS of $2^{31}-1$ by MZM.

Fig. 9 presents the BER performance of $10 \mathrm{~Gb} / \mathrm{s}$ OOK downstream signal under the $\mathrm{B} 2 \mathrm{~B}$ and transmission over a length of $20 \mathrm{~km} \mathrm{SMF}{ }_{1}$. Here, the received sensitivity of $-27.2 \mathrm{dBm}$ is measured after the $\mathrm{SMF}_{1}$. As shown in Fig. 4, the power penalty was $0.3 \mathrm{~dB}$ at the BER of $10^{-9}$. Besides, the corresponding eye diagrams are also shown in the insets of Fig. 9. The two eyes are clean and wide-opening.

Next, we report transmission of the $10 \mathrm{~Gb} / \mathrm{s}$ DPSK downstream signal in the proposed PON system. A DFB-LD was 


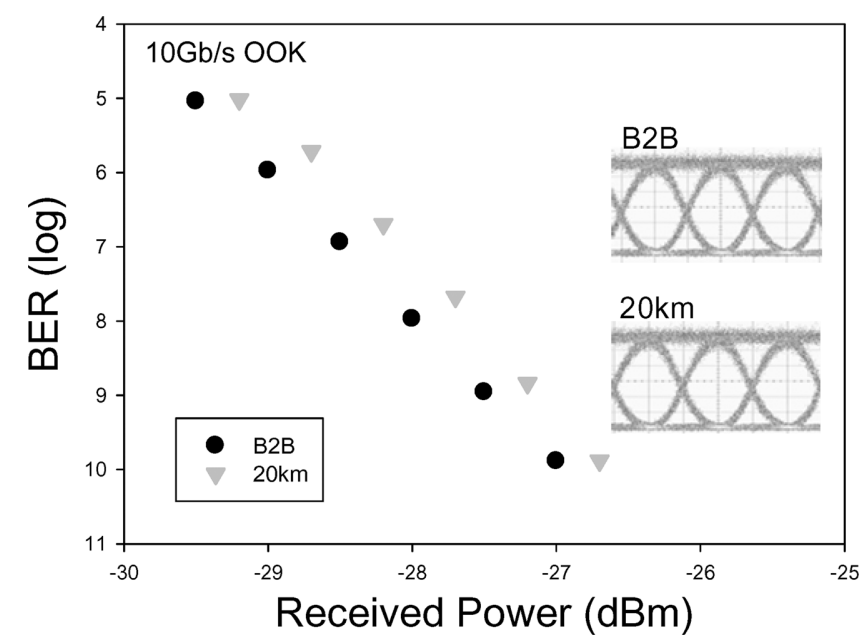

Fig. 9. BER performance of $10 \mathrm{~Gb} / \mathrm{s}$ OOK downstream under the B2B and $20 \mathrm{~km} \mathrm{SMF}{ }_{1}$ transmission.

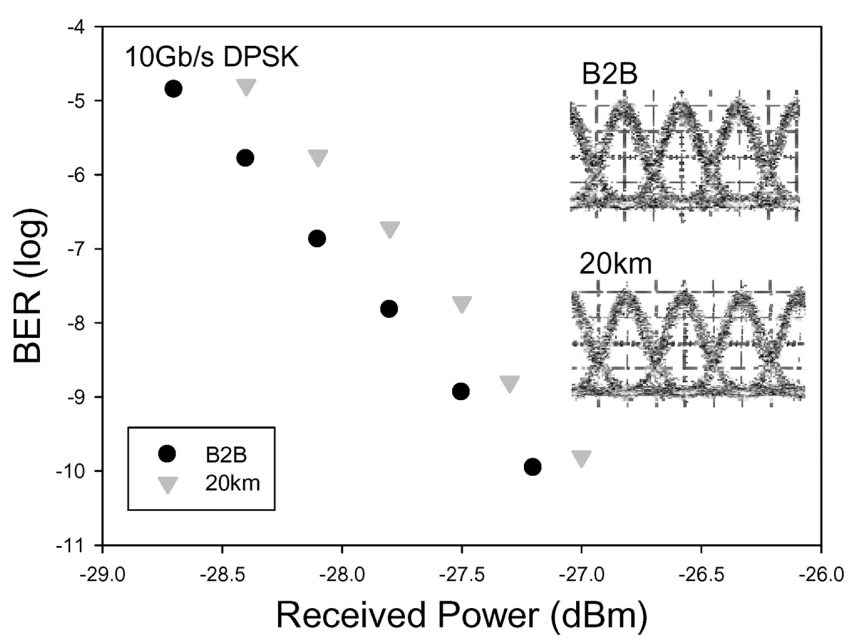

Fig. 10. BER performance of $10 \mathrm{~Gb} / \mathrm{s}$ DPSK downstream under the B2B and $20 \mathrm{~km} \mathrm{SMF}_{1}$ transmission.

modulated at $10 \mathrm{~Gb} / \mathrm{s}$ DPSK format via a $10 \mathrm{GHz} \mathrm{LiNbO}_{3}$ phase modulator (PM) for downstream traffic in the proposed ring WDM-PON. The PM was driven by a differentially precoded 10 $\mathrm{Gb} / \mathrm{s}$ at PRBS-NRZ with $2^{31}-1$ pattern length. The downstream DPSK signal launched into the ONU and was received by an optically preamplified receiver $(\mathrm{Rx})$, consisting of a VOA, an EDFA, a delayed interferometer for DPSK demodulation, and a $10 \mathrm{GHz}$ PIN. The BER measurements of the downstream signals at the $\mathrm{B} 2 \mathrm{~B}$ and $20 \mathrm{~km} \mathrm{SMF}{ }_{1}$ transmission are shown in Fig. 10. The insets of Fig. 10 are the corresponding eye diagrams. As shown in Fig. 10, error free operation is observed in each case with clear and wide open eye. Here, the Rx sensitivity of $-27.3 \mathrm{dBm}$ was measured after transmission over $20 \mathrm{~km}$ of $\mathrm{SMF}_{1}$ using single-end detection. Besides, we achieved $0.4 \mathrm{~dB}$ of power penalty at the BER of $10^{-9}$ for the downstream DPSK signal.

Finally, we will demonstrate $10 \mathrm{~Gb} / \mathrm{s}$ 16-QAM OFDM downstream signal by using a $2.5 \mathrm{GHz}$ bandwidth-DFB-LD via direct

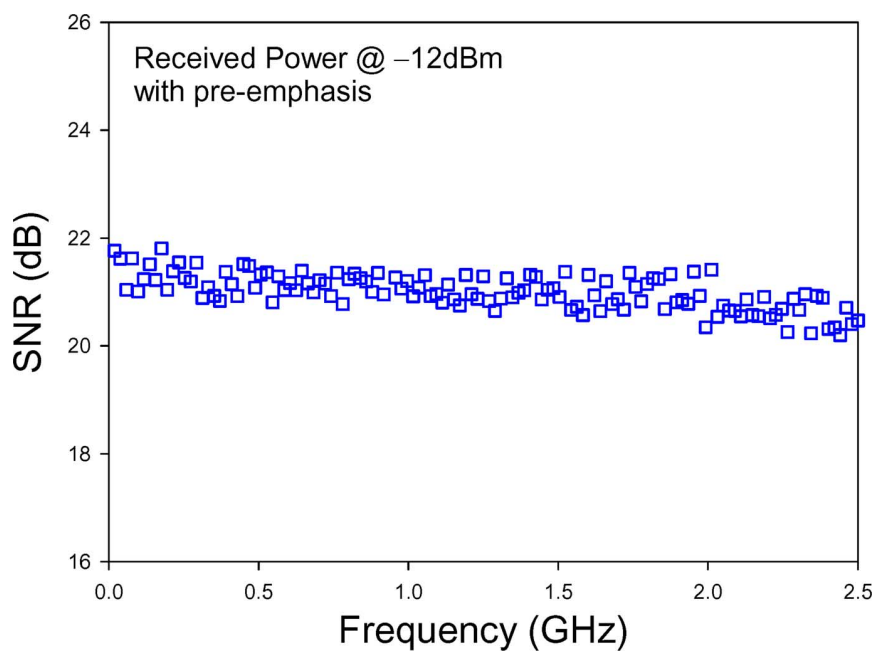

Fig. 11. Measured SNR of each OFDM subcarrier in the frequency bandwidth of $0.0195-2.50 \mathrm{GHz}$ after $20 \mathrm{~km} \mathrm{SMF}_{1}$ transmission.

modulation. Here, we did not need an external modulator to generate traffic rate at $10 \mathrm{~Gb} / \mathrm{s}$. Since the OFDM signal is very spectral efficient, $10 \mathrm{~Gb} / \mathrm{s}$ data rate can be achieved via a DML.

In the measurement, the OFDM signal was produced by MATLAB program, and was applied to the DML using an AWG. The signal processing of the OFDM consisted of serial-to-parallel conversion, QAM symbol encoding, IFFT, CP insertion, and DA conversion. The sampling rate and DAC resolution of AWG were $12 \mathrm{GS} / \mathrm{s}$ and 8 bits. The FFT size and IFFT size are both 512, and CP length is 1/64. Besides, 107 OFDM subcarriers of 16-QAM OFDM modulation format only occupied in $2.5 \mathrm{GHz}$ of bandwidth from $1.95 \mathrm{MHz}$ to $2.50 \mathrm{GHz}$. The $10 \mathrm{~Gb} / \mathrm{s}$ downstream signal was achieved using a $2.5 \mathrm{GHz}$ DML. The received downstream OFDM signal was captured by a digital oscilloscope with sampling rate of $50 \mathrm{GS} / \mathrm{s}$ and a $3 \mathrm{~dB}$ bandwidth of $12.5 \mathrm{GHz}$ for OFDM signal demodulation. To demodulate the vector signal, the offline DSP program was employed. The demodulation process included synchronization, FFT, one-tap equalization, and QAM symbol decoding. The FFT size was 512. Finally, the BER was calculated based on the measured SNR.

As we know, higher SNR would result in better BER performance. The SNR required to achieve the FEC threshold (BER of $3.8 \times 10^{-3}$ ) is $16.5 \mathrm{~dB}$, when 16-QAM OFDM is used. Besides, the pre-emphasis can properly arrange the electrical power of each subcarrier to obtain the better SNR. In Fig. 11, we show the measured SNR of 16-QAM OFDM subcarriers in the frequency from $1.95 \mathrm{MHz}$ to $2.50 \mathrm{GHz}$ after transmission over 20 $\mathrm{km}$ of $\mathrm{SMF}_{1}$. The optical received power was $-12 \mathrm{dBm}$ for this case. As shown in our later analysis, the average BER including all the OFDM subcarriers is still lower than the FEC threshold. Hence, we do not sacrifice any bandwidth by using the proposed PON network.

Fig. 12 shows the BER measurement result of $1532.2 \mathrm{~nm}$ downstream signal using optical 16-QAM OFDM at the B2B and after transmission over $20 \mathrm{~km} \mathrm{SMF}_{1}$ via a DML. The corresponding $\mathrm{Rx}$ sensitivities are -19.2 and $-18.4 \mathrm{dBm}$ at the BER of $3.8 \times 10^{-3}$, respectively. The power penalty is $0.8 \mathrm{~dB}$. 
TABLE I

Comparison of Different Modulations Used in the Proposed Scheme

\begin{tabular}{|c|c|c|c|c|c|c|c|c|c|}
\hline & Modulation & $\begin{array}{c}\text { Bit } \\
\text { Rate } \\
(\mathrm{Gb} / \mathrm{s})\end{array}$ & $\begin{array}{c}\text { Required } \\
\text { Bandwidth } \\
(\mathrm{GHz})\end{array}$ & $\begin{array}{c}\mathrm{Rx} \\
\text { Sensitivity } \\
\text { after } 20 \\
\mathrm{~km} \mathrm{SMF} \\
(\mathrm{dBm})\end{array}$ & $\begin{array}{c}\text { Power } \\
\text { Penalty } \\
\text { after } 20 \mathrm{~km} \\
\text { SMF (dB) }\end{array}$ & $\begin{array}{l}\text { Injection } \\
\text { Optical } \\
\text { Power } \\
(\mathrm{dBm})\end{array}$ & Modulator & $\begin{array}{c}\text { ONU } \\
\text { supported } \\
\text { (without } \\
\text { optical } \\
\text { amplifiers) }\end{array}$ & Complexity \\
\hline \multirow[t]{2}{*}{$\begin{array}{l}\text { Up- } \\
\text { stream }\end{array}$} & OOK & 2.5 & 1.2 & $\begin{array}{c}-24.7 @ \\
\text { BER 1e-9 }\end{array}$ & 0.4 & $>-10$ & RSOA & 7 & Simple \\
\hline & $\begin{array}{c}\text { OFDM-64 } \\
\text { QAM }\end{array}$ & 10 & 1.2 & $\begin{array}{c}-12.4 @ \\
\text { BER 3.8e- } \\
3\end{array}$ & 0 & $>-8$ & RSOA & 3 & $\begin{array}{c}\text { Complicated } \\
\text { (require DSP) }\end{array}$ \\
\hline \multirow[t]{3}{*}{$\begin{array}{l}\text { Down- } \\
\text { stream }\end{array}$} & OOK & 10 & 10 & $\begin{array}{c}-27.2 @ \\
\text { BER 1e-9 }\end{array}$ & 0.3 & N.A. & MZM & 9 & Simple \\
\hline & DPSK & 10 & 10 & $\begin{array}{c}-27.3 @ \\
\text { BER 1e-9 }\end{array}$ & 0.4 & N.A. & PM & 9 & $\begin{array}{l}\text { Complicated } \\
\text { (require DI for } \\
\text { DPSK } \\
\text { demodulaiton) }\end{array}$ \\
\hline & $\begin{array}{l}\text { OFDM-16 } \\
\text { QAM }\end{array}$ & 10 & 2.5 & $\begin{array}{c}-18.4 @ \\
\text { BER 3.8e- } \\
3\end{array}$ & 0.8 & N.A. & DML & 6 & $\begin{array}{l}\text { Complicated } \\
\text { (require DSP) }\end{array}$ \\
\hline
\end{tabular}

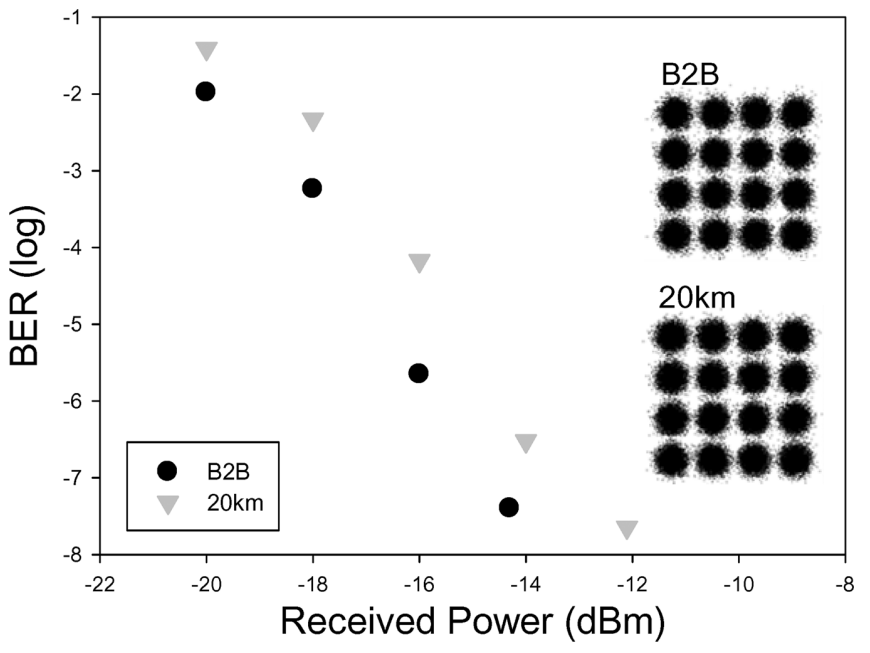

Fig. 12. BER measurements of $1532.2 \mathrm{~nm}$ downstream signal using optical 16-QAM OFDM at the B2B and after transmission over $20 \mathrm{~km} \mathrm{SMF1} \mathrm{via} \mathrm{a}$ DML.

The insets of Fig. 12 show the corresponding constellation diagrams of 16-QAM OFDM signals.

We can also use a $10 \mathrm{GHz}$ bandwidth optical modulator to increase the downstream rate by OAM-OFDM modulation in the proposed ring-based WDM-PON architecture. In the past, 40 $\mathrm{Gb} / \mathrm{s}$ OFDM downstream traffic has been proposed and demonstrated by another group of our institute (ITRI) [30]. However, the received sensitivity was measured at $-8 \mathrm{dBm}$ in their proposed modulation scheme after transmission through $20 \mathrm{~km}$ of SMF. This is because the RF power fading and fiber dispersion at high OFDM modulated rate. Their scheme can thus only support a few ONUs if it is implemented in our proposed ring-based WDM-PON system.
Comparing the $10 \mathrm{~Gb} / \mathrm{s}$ OOK, $10 \mathrm{~Gb} / \mathrm{s}$ DPSK, and $10 \mathrm{~Gb} / \mathrm{s}$ 16-QAM OFDM modulation schemes for the downstream traffic, we determined the received sensitivities to be -27.2 , -27.3 , and $-18.4 \mathrm{dBm}$, respectively, after $20 \mathrm{~km}$ fiber transmission, as mentioned previously. The comparison of different modulations used in the proposed scheme is summarized in Table I.

In the proposed scheme, each ONU provides an insertion loss of about $3.2 \mathrm{~dB}$. This is contributed by two SWs (1 dB loss), two FBGs (0.2 dB loss), and two OCs (2 dB loss). It is worth to note that for the "target ONU" or "pass through ONU," the wavelength only needs to pass through 2 OCs. When the downstream signal of $7.5 \mathrm{dBm}$ is transmitted from the $\mathrm{CO}$, by considering the $5 \mathrm{~dB}$ insertion loss of the $20 \mathrm{~km} \mathrm{SMF}$, and the Rx sensitivities of $-27.2 \mathrm{dBm}$ (OOK), $-27.3 \mathrm{dBm}$ (DPSK), and $-18.4 \mathrm{dBm}(\mathrm{OFDM})$, the power budgets are $-29.7 \mathrm{dBm}$ (OOK), -26.6 dBm (DPSK), and $-20.9 \mathrm{dBm}$ (OFDM) respectively. Hence, the numbers of supported ONUs are 9, 9 , 6 when using downstream OOK, downstream DPSK, and downstream OFDM-QAM respectively. When the upstream signal of $3 \mathrm{dBm}$ is transmitted from the ONU, by considering the $5 \mathrm{~dB}$ insertion loss of the $20 \mathrm{~km} \mathrm{SMF}$, and the Rx sensitivities of $-24.7 \mathrm{dBm}$ (OOK) and -12.4 (OFDM), the power budgets are $-22.7 \mathrm{dBm}$ (OOK) and - 10.4 dBm (OFDM), respectively. Hence, the numbers of supported ONUs are 7 and 3 when using upstream OOK and upstream OFDM, respectively.

We can observe from the analysis listed in Table I that the numbers of supported ONUs are determined by the upstream power budget. To increase the numbers of supported ONUs in the proposed system, EDFA can be used to compensate the losses of fiber and passive components (as shown in Fig. 2). We can also observe that although OFDM modulation can reduce the modulation bandwidth required in the modulators, it 
degrades the Rx sensitivity of the signal and, hence, reduces the numbers of supported ONUs.

\section{CONCLUSION}

We have proposed and experimentally demonstrated a ring-based WDM-PON providing both RB noise mitigation and fiber-fault protection. The proposed dual-ring-based WDM-PON could be used to protect and restore the fiber-fault. Besides, the ring-based architecture also could mitigate the $\mathrm{RB}$ beat noise, since the RB and the upstream wavelengths were propagating in opposite directions. In the proposed PON system, we discussed and analyzed characteristics of the downstream signal using $10 \mathrm{~Gb} / \mathrm{s}$ OOK, $10 \mathrm{~Gb} / \mathrm{s}$ DPSK, and $10 \mathrm{~Gb} / \mathrm{s}$ OFDM modulations, respectively. And, the received sensitivities of $-27.2 \mathrm{dBm}$ (at BER of $10^{-9}$ ), $-27.3 \mathrm{dBm}$ (at BER of $10^{-9}$ ), and $-18.4 \mathrm{dBm}$ (at BER of $3.8 \times 10^{-3}$ (FEC level)) were observed, respectively, after $20 \mathrm{~km}$ fiber transmission. Hence, the sensitivity of OOK format was better than that of DPSK and OFDM. However, the OFDM modulation only needed a lower cost DML to achieve $10 \mathrm{~Gb} / \mathrm{s}$ downstream rate. It is also shown that the three aforementioned downstream modulation schemes could provide the required eight, seven, and six ONUs in the proposed PON network respectively without requiring additional EDFA units. Of course, if we want to support more ONUs in our proposed network, EDFA could be used.

Moreover, we also investigate the upstream traffic of the 2.5 $\mathrm{Gb} / \mathrm{s}$ OOK and $10 \mathrm{~Gb} / \mathrm{s}$ 64-QAM OFDM by using the directly modulated RSOA-based ONU, respectively. Here, the required injection powers were -10 and $-8 \mathrm{dBm}$ after $20 \mathrm{~km}$ fiber link, respectively. Besides, the measured sensitivities are -24.7 and $-12.4 \mathrm{dBm}$. Meanwhile, using OFDM modulation can increase the upstream rate by four times comparing with OOK format. It, however, also results in the received sensitivity to drop by half.

\section{REFERENCES}

[1] G. Talli and P. D. Townsend, "Hybrid DWDM-TDM long reach PON for next generation optical access," J. Lightw. Technol., vol. 24, no. 7, pp. 2827-2834, Jul. 2006.

[2] C.-H. Yeh, C.-S. Lee, and S. Chi, "Simple self-restored ring-based time division multiplexed passive optical network," J. Opt. Netw., vol. 7, pp. 288-293, 2008.

[3] C.-C. Lin, H.-H. Lu, W.-J. Ho, H.-C. Peng, and C.-Y. Li, "A bidirectional WDM transport system based on RSOAs and optoelectronic feedback technique," IEEE Commun. Lett., vol. 14, no. 10, pp. 969-971, Oct. 2010.

[4] C. H. Yeh, C. W. Chow, H. Y. Chen, and B. W. Chen, "Using adaptive four-band OFDM modulation with $40 \mathrm{~Gb} / \mathrm{s}$ downstream and $10 \mathrm{~Gb} / \mathrm{s}$ upstream signals for next generation long-reach PON," Opt. Exp., vol. 19 , pp. 26150-26160, 2011

[5] C. W. Chow, L. Xu, C. H. Yeh, H. K. Tsang, W. Hofmann, and M. C. Amann, " $40 \mathrm{~Gb} / \mathrm{s}$ upstream transmitters using directly-modulated 1.55 $\mu \mathrm{m}$ VCSEL array for high-split-ratio PONs," IEEE Photon. Technol. Lett., vol. 22, no. 5, pp. 347-349, Mar. 2010.

[6] S. L. Lee, "Performance enhancement of WDM-PON systems with DMLs and RSOAs," presented at the Annu. Wireless and Opt. Commun. Conf., Taichung, Taiwan, 2008, Invited Paper.
[7] A. Borghesani, I. F. Lealman, A. Poustie, D. W. Smith, and R. Wyatt, "High temperature, colourless operation of a reflective semiconductor optical amplifier for $2.5 \mathrm{Gbit} / \mathrm{s}$ upstream transmission in a WDM-PON," in Proc. Eur. Conf. Exhib. Opt. Commun., 2007, pp. 641-642.

[8] C. H. Yeh, C. W. Chow, Y. L. Liu, and C. L. Pan, " 40 Gb/s on-off keying downstream and $10 \mathrm{~Gb} / \mathrm{s}$ on-off keying remodulated upstream signals in long-reach access network with multi-video services," Opt. Eng., vol. 50, p. 125008, 2011.

[9] D. Qian, N. Cvijetic, J. Hu, and T. Wang, "40-Gb/s MIMOOFDM-PON using polarization multiplexing and direct-detection," presented at the Opt. Fiber Commun. Conf., San Diego, CA, 2009, Paper OMV3.

[10] H.-H. Lin, C.-Y. Lee, S.-C. Lin, S. L. Lee, and G. Keiser, "WDM-PON systems using cross-remodulation to double network capacity with reduced Rayleigh scattering effects," presented at the Opt. Fiber Commun. Conf., San Diego, CA, 2008, Paper OTuH6.

[11] C. H. Yeh, C. W. Chow, and H. Y. Chen, "Simple colorless WDM-PON with Rayleigh backscattering noise circumvention employing m-QAM OFDM downstream and remodulated OOK upstream signals," $J$. Lightw. Technol., vol. 30, no. 13, pp. 2151-2155, Jul. 2012.

[12] C. W. Chow and C. H. Yeh, "Mitigation of Rayleigh backscattering in 10-Gb/s downstream and 2.5-Gb/s upstream DWDM 100-km longreach PONs," Opt. Exp., vol. 19, pp. 4970-4976, 2011.

[13] C. W. Chow, G. Talli, and P. D. Townsend, "Rayleigh noise reduction in $10-\mathrm{Gb} / \mathrm{s}$ DWDM-PONs by wavelength detuning and phase-modulation-induced spectral broadening," IEEE Photon. Technol. Lett., vol. 19, no. 6, pp. 423-425, Mar. 2007.

[14] Z. Li, Y. Dong, Y. Wang, and C. Lu, "A novel PSK Manchester modulation format in $10-\mathrm{Gb} / \mathrm{s}$ passive optical network system with high tolerance to beat interference noise," IEEE Photon. Technol. Lett., vol. 17, no. 5, pp. 1118-1120, May 2005.

[15] S.-M. Lee, K.-M. Choi, S.-G. Mun, J.-H. Moon, and C.-H. Lee, "Dense WDM-PON based on wavelength locked Fabry-Perot lasers," presented at the Opt. Fiber Commun. Conf., Anaheim, CA, 2005, Paper JWA55.

[16] J. L. Wei, E. Hugues-Salas, R. P. Giddings, X. Q. Jin, X. Zheng, S. Mansoor, and J. M. Tang, "Wavelength reused bidirectional transmission of adaptively modulated optical OFDM signals in WDM-PONs incorporating SOA and RSOA intensity modulators," Opt. Exp., vol. 18, pp. 9791-9808, 2010.

[17] C. H. Yeh, C. W. Chow, H. Y. Chen, and J. Y. Sung, "Hybrid OFDMbased multi-band wireless and baseband signal transmission in PON access," Electron. Lett., vol. 48, pp. 390-392, 2012.

[18] W.-R. Peng, K.-M. Feng, A. E. Willner, and S. Chi, "Estimation of the bit error rate for direct-detected OFDM signals with optically preamplified receivers," J. Lightw. Technol., vol. 27, no. 10, pp. 1340-1346, May 2009.

[19] J. Yu, M. F. Huang, D. Qian, L. Chen, and G.-K. Chang, "Centralized lightwave WDM-PON employing 16-QAM intensity modulated OFDM downstream and OOK modulated upstream signals," IEEE Photon. Technol. Lett., vol. 20, no. 18, pp. 1545-1547, Sep. 2008.

[20] D. Qian, S. H. Fan, N. Cvijetic, J. Hu, and T. Wang, "64/32/16 QAMOFDM using direct-detection for 40G-OFDMA-PON downstream," presented at the Opt. Fiber Commun. Conf., Los Angeles, CA, 2011, Paper OMG4.

[21] C. H. Yeh, C. W. Chow, F. Y. Shih, Y. F. Wu, and J. Y. Sung, "Fiberfault protection WDM-PON using new apparatus in optical networking unit," Opt. Commun., vol. 285, pp. 1803-1806, 2012.

[22] Z. X. Wang, X. F. Sun, C. Lin, C. K. Chan, and L. K. Chen, “A novel centrally controlled protection scheme for traffic restoration in WDM passive optical networks," IEEE Photon. Technol. Lett., vol. 17, no. 3, pp. 717-719, Mar. 2005.

[23] A. Chowdhury, H.-C. Chien, S.-H. Fan, C. Liu, C. Su, and G.-K. Chang, "A survivable protection and restoration scheme using wavelength switching of integrated tunable optical transmitter for high throughput WDM-PON system," presented at the Opt. Fiber Commun. Conf., Los Angeles, CA, 2011, Paper OThK6.

[24] J. Chen, L. Wosinska, and S. He, "High utilization of wavelengths and simple interconnection between users in a protection scheme for passive optical networks," IEEE Photon. Technol. Lett., vol. 20, no. 6, pp. 389-391, Mar. 2008. 
[25] C.-H. Yeh and S. Chi, "Self-healing ring-based time-sharing passive optical networks," IEEE Photon. Technol. Lett., vol. 19, no. 15, pp. 1139-1141, Aug. 2007.

[26] A. Yariv, H. Blauvelt, and S. W. Wu, "A reduction of interferometric phase-to-intensity conversion noise in fiber links by large index phase modulation of the optical beam," J. Lightw. Technol., vol. 10, no. 7, pp. 978-981, Jul. 1992.

[27] J. Prat, J. Lazaro, P. Chanclou, R. Soila, P. Velanas, A. Teixeira, G. T. Beleffi, I. Tomkos, and D. Klonidis, "Hybrid ring-tree WDM/TDM-PON optical distribution network," presented at the Int. Conf. Transp. Opt. Netw., Azores, Portugal, 2009, Paper Th.B3.1.

[28] C.-H. Yeh, C.-W. Chow, C.-H. Wang, F.-Y. Shih, H.-C. Chien, and S Chi, "A self-protected colorless WDM-PON with $2.5 \mathrm{~Gb} / \mathrm{s}$ upstream signal based on RSOA," Opt. Exp., vol. 16, pp. 12296-12301, 2008.

[29] C. H. Yeh, C. W. Chow, F. Y. Shih, C. H. Wang, Y. F. Wu, and S. Chi, "Wavelength tunable laser for signal remodulation in WDM access networks using DPSK downlink and OOK uplink," IEEE Photon. Technol. Lett., vol. 21, no. 22, pp. 1710-1712, Nov. 2009.

[30] H.-Y. Chen, C.-C. Wei, D.-Z. Hsu, M. C. Yuang, J. Chen, Y.-M. Lin, P.-L. Tien, S. S. W. Lee, S.-H. Lin, W.-Y. Li, C.-H. Hsu, and J.-L. Shih, "A 40-Gb/s OFDM PON system based on 10-GHz EAM and 10-GHz direct-detection PIN," IEEE Photon. Technol. Lett., vol. 24, no. 1, pp. 85-87, Jan. 2012.
[31] J. Prat, J. A. Lazaro, K. Kanonakis, and I. Tomokos, "New FTTH architectures for NG-PON-2," presented at the Access Netw. In-House Commun., OSA Tech. Digest, Karlsruhe, Germany, ATuA4.

[32] J. Prat, J. Lazaro, P. Chanclou, R. Soila, A. M. Gallardo, A. Teixeira, G. M. TosiBeleffi, and I. Tomkos, "Results from EU project SARDANA on $10 \mathrm{G}$ extended reach WDM PONs," presented at the Opt. Fiber Commun. Conf., San Diego, CA, 2010, Paper OThG5.

[33] F. T. An, K. S. Kim, D. Gutierrez, S. Yam, E. Hu, K. Shrikhande, and L. G. Kazovsky, "SUCCESS: A next-generation hybrid WDM/TDM optical access network architecture," J. Lightw. Technol., vol. 22, no. 11, pp. 2557-2569, Nov. 2004.

[34] M. Matsuura and E. Oki, "Carrier wavelength reuse of multicarrier distributed OADM network using optical carrier regeneration," presented at the Eur. Conf. Exhib. Opt. Commun., Torino, Italy, 2010, Paper We.7.D.4.

[35] R. A. Shafik, M. S. Rahman, and A. R. Islam, "On the extended relationships among EVM, BER and SNR as performance metrics," in Proc. Int. Conf. Environ. Civil Eng., 2006, pp. 408-411.

Author biographies not included by author request due to space constraints. 